\title{
O afastamento do trabalho por LER/DORT: repercussões na saúde mental
}

\author{
The work retirement due to RSI/WMSD: \\ impact on mental health
}

Maria do Carmo Baracho de Alencar ${ }^{1}$, Natacha Harumi Ota ${ }^{2}$

ALENCAR, M. C. B.; OTA, N. H. O afastamento do trabalho por LER/DORT: repercussões na saúde mental. Rev. Ter. Ocup. Univ. São Paulo, v. 22, n. 1, p. 60-67, jan./abr. 2011.

RESUMO: O objetivo deste estudo foi o de investigar sobre aspectos relacionados ao afastamento do trabalho por LER/DORT e discutir sobre as repercussões na saúde mental dos trabalhadores, a partir das percepções subjetivas dos sujeitos. O estudo é exploratório e descritivo e com dados qualitativos. Foram selecionados trabalhadores afastados do trabalho por LER/DORT através de registros de pacientes atendidos em atividades de estágio do curso de Terapia Ocupacional da Universidade Federal de São Paulo, no ano de 2009. Foi elaborado um roteiro e realizadas entrevistas semiestruturadas sobre as percepções de como era seu trabalho, como adoeceu, situações e dificuldades vivenciadas no trabalho e atuais. As entrevistas foram gravadas e transcritas para análise de conteúdo. Participaram do estudo cinco (5) sujeitos, de ambos os gêneros, com idade entre 36 e 52 anos. Verificou-se desgaste e sofrimento em relação a alguns aspectos da organização do trabalho, presença de dores osteomusculares no trabalho, invisibilidade dos sintomas e da doença, dificuldades funcionais nas atividades de vida diária, entre outros. $\mathrm{O}$ estudo promove algumas reflexões acerca do processo de adoecimento e afastamento do trabalho por LER/DORT e das repercussões na saúde mental.

DESCRITORES: Licença médica; Transtornos traumáticos cumulativos; Saúde mental; Trabalho/ psicologia; Terapia ocupacional.

\footnotetext{
1 Docente do Departamento de Ciências da Saúde da Universidade Federal de São Paulo, Campus da Baixada Santista.

2. Acadêmica do curso de Terapia Ocupacional da Universidade Federal de São Paulo, Iniciação Científica.

Endereço para correspondência: Maria do Carmo Baracho de Alencar. Rua Prof. Torres Homem, 675, apto.72. Aparecida - Santos, SP. CEP: 11.025.021. e.mail: belinha.alencar1@gmail.com
} 


\section{INTRODUÇÃO}

$\mathrm{O}$ mundo do trabalho tem sofrido intensas mudanças advindas do processo de globalização, com inovações tecnológicas, mudanças nos processos e modos de organização do trabalho, exigências de qualidade e produtividade promovendo novas exigências junto aos trabalhadores, que encontram dificuldades na estabilidade de cargos, e estão, muitas vezes, em trabalhos terceirizados, quarteirizados, entre outros e que vem afetando a saúde dos trabalhadores, tanto no aspecto físico quanto mental (LANCMAN, 2004). Uma das formas de adoecimento relacionado ao trabalho contemporâneo são as lesões por esforços repetitivos (LER) ou distúrbios osteomusculares relacionados ao trabalho (DORT), que vem crescendo entre a população de trabalhadores. No Brasil, começou a adquirir expressão em número e relevância social a partir da década de 1980, tornando-se um grave problema de saúde pública e social em função da sua magnitude e abrangência (BRASIL, 2001).

Essa afecção ou doença era conhecida somente pela terminologia de LER- Lesão por esforço repetitivo, porém a terminologia DORT- Distúrbio osteomuscular relacionado ao trabalho, segundo a Instrução Normativa INSS/DC N ${ }^{\circ}$ 98 de 2003, tem sido utilizada por muitos autores por não apontar causas definidas (ex: esforço repetitivo), nem os efeitos (ex: lesão). A terminologia LER/DORT é atualmente utilizada pelo Ministério da Saúde e Previdência Social (BRASIL, 2001).

Tais transtornos tem o aparecimento e evolução de caráter insidioso, e origem multifatorial complexa (BRASIL, 2001). Os DORTs são danos decorrentes de um esforço excessivo imposto ao sistema musculoesquelético e da falta de tempo para sua recuperação. Seus sintomas são: dor, parestesia, sensação de peso e fadiga (BRASIL, 2006). A alta prevalência das LER/DORT tem sido explicada pelas transformações no mundo do trabalho, onde a organização tem se caracterizada por estabelecimento de metas e produtividade, entre outros, e sem levar em conta os trabalhadores e seus limites físicos (BRASIL, 2006). Pastre et al. (2007) citam que tais distúrbios podem causar desordens motoras e mentais, resultando em queda de produção e até afastamento do trabalho.

A organização do trabalho prescreve as normas e parâmetros das empresas, quem deve executar as tarefas, de que forma e quando, qual a qualidade exigida, equipamentos necessários e disponíveis, e quantidades a serem produzidas, entre outros. Merlo et al. (2003) citam elementos da organização do trabalho relacionados às LER/DORTs, como a pressão no trabalho, restrição da comunicação entre os trabalhadores, pouco reconhecimento no trabalho e o não emprego de novas tecnologias para aliviar a carga de trabalho, entre outros. De acordo com Ghisleni e Merlo (2005), são afecções que expressam sofrimentos advindos da relação do trabalhador com o trabalho e podem ser consideradas um problema de saúde pública.

Frederick Taylor, engenheiro norte-americano, responsável pela Organização Científica do Trabalho (OCT), no final do século XIX, buscou aumentar a produtividade por meio da execução de tarefas individualizadas e fragmentadas. Realizou estudos acerca de controle de tempos e movimentos visando reduzir tempos gastos em tarefas, entre outros; e não analisou os aspectos humanos implicados no processo produtivo. $\mathrm{O}$ modelo taylorista contribuiu, por um lado, para o crescimento da produtividade, mas por outro lado, trouxe repercussões negativas à saúde dos trabalhadores (MERLO; LÁPIS, 2005). Para Lancman e Uchida (2003) Taylor, aparentemente buscou eliminar a subjetividade do trabalho através do controle de corpos e mentes dos trabalhadores. Na mesma época segundo Silva et al (2009), surgiu o fordismo. Criado por Henry Ford, esse movimento consistiu em inovações tecnológicas e econômicas caracterizada pela produção em massa. Para Merlo e Lápis (2005) com o fordismo houve a conexão entre as diferentes tarefas, criando as esteiras rolantes e a parcelização das tarefas e divisão do trabalho foram ainda mais intensificadas, com controle de tempos ociosos através de dispositivos eletrônicos, submetendo o operário a ritmos automáticos, à cadência de máquinas. A Organização Científica do Trabalho (OCT), que teve grandes avanços nas primeiras décadas do século XX, foi representada pelos dois modelos taylorismo e fordismo.

A partir da década de 1950, surgiu uma nova forma de organização do trabalho, o Toyotismo, concebida na Toyota Motor Co., tendo como figura principal o engenheiro Taiichi Ohno, se tornou, a partir da década de 1970, conhecida como modelo japonês. Apresenta formas de organização do trabalho e qualificação do trabalho distintas do modelo anterior e fundadas na diversificação das tarefas e envolvimento do trabalhador com os objetivos da empresa (MERLO; LÁPIS, 2005).

A consolidação deste modelo se relaciona com tentativas de potencializar ao máximo o rendimento do trabalho vivo. As características principais deste modelo são trabalho em equipe, management of stress, flexibilidade da força de trabalho, subcontratação e gerenciamento participativo, automação, entre outros. Exige-se um trabalhador polivalente, multifuncional, e que opere em várias máquinas, atuando como membro de equipe de operários, se contrapondo à proposta do fordismo de 
trabalho em posto fixo (OLIVEIRA, 2004). Em relação ao Toyotismo, Merlo e Lápis (2005) citam que formas de controle autoritárias são transformadas em lideranças motivadoras, onde o próprio grupo exerce pressão sobre si mesmo. Algumas técnicas utilizadas no Toyotismo servem para indicar os trabalhadores desinteressados, localizar pessoal em excesso, possibilitar pressões de toda a ordem (OLIVEIRA, 2004).

A análise da organização do trabalho deve levar em conta: a organização do trabalho prescrita (formalizada pela empresa) e a organização do trabalho real (o modo operatório dos trabalhadores). Para Dejours (1992) o descompasso entre as duas favoreceria o aparecimento do sofrimento mental. Este sofrimento comumente não se manifesta porque os sujeitos tentam se proteger e se defender. Há necessidade de um equilíbrio entre as forças que tentam desestabilizar o sujeito e o esforço deste para se manter tanto produtivo quanto "saudável".

Há o sofrimento patogênico e o sofrimento criativo. O sofrimento é considerado criativo quando o trabalho é reconhecido e todo o investimento pessoal, que foi demandado e que de certa forma gerou sofrimento, tem um sentido (DEJOURS et al., 1994). A patologia surge quando se rompe o equilíbrio e o sofrimento não é mais contornável, quando são utilizados todos os recursos psicoafetivos e intelectuais para dar conta das demandas impostas pela organização do trabalho, mas nada se pode fazer para modificar ou adaptar o trabalho (LANCMAN; UCHIDA, 2003). Para Dejours (2004) a patologia surge quando não há nada além de pressões fixas, rígidas, o aborrecimento, o medo, ou o sentimento de impotência, entre outros.

No mundo contemporâneo, as LER/DORT têm acometido homens e mulheres em plena fase produtiva, e têm causado inúmeros afastamentos do trabalho, cuja quase totalidade evolui para incapacidade parcial e, em alguns casos, para a incapacidade permanente, com aposentadoria por invalidez (BRASIL, 2002). As LER/DORT, além dos transtornos psíquicos são hoje as principais causas de afastamento do trabalho e de aposentadorias precoces, causando impactos nas contas do INSS (LANCMAN, 2008). O afastamento do trabalho causa um impacto que é maior para o indivíduo, no que diz respeito ao desempenho de seu papel social e função na vida cotidiana (SILVA et al., 2007)

O objetivo deste estudo foi investigar os aspectos relacionados ao afastamento do trabalho por LER/DORT, a partir das percepções dos trabalhadores e discutir suas repercussões na sua saúde mental.
O estudo é qualitativo, exploratório e descritivo. Foram selecionados trabalhadores afastados do trabalho com diagnósticos médicos estabelecidos para LER/DORTs. A seleção ocorreu por meio de análises de avaliações, nas quais constavam os registros com nomes, endereços e telefones, diagnósticos médicos, entre outros realizadas em atividades de estágio profissionalizante da área de "Saúde e Trabalho", do curso de Terapia Ocupacional da Universidade Federal de São Paulo, no ano de 2009. Posteriormente, foi realizado, o contato telefônico junto a cinco (05) trabalhadores afastados para convidá-los a participar da pesquisa e para a realização de entrevistas semiestruturadas e gravadas. $\mathrm{O}$ roteiro elaborado para as entrevistas contemplou dados gerais (nome e data da entrevista), dados demográficos (idade, gênero, escolaridade, estado civil), última profissão/ função, escolaridade, diagnóstico clínico e tempo de afastamento. Posteriormente, o entrevistado foi convidado a discorrer sobre: o seu trabalho; como adoeceu e situações e dificuldades vivenciadas no trabalho. As entrevistas foram gravadas e tiveram duração aproximada de 60 minutos. Posteriormente foram transcritas na íntegra para análise de conteúdo. As entrevistas ocorreram no segundo semestre de 2010, na residência dos sujeitos ou no laboratório do curso de Terapia Ocupacional. A análise foi organizada em três etapas, sugeridas por Bardin (2010): pré-análise, exploração do material, tratamento dos resultados obtidos e interpretação. Os elementos encontrados foram organizados por categorias temáticas, para as análises e discussões.

O projeto foi aprovado pelo Comitê de Ética em pesquisa da Universidade Federal de São Paulo $(1271 / 10)$.

\section{RESULTADOS E DISCUSSÃO}

Participaram do estudo cinco trabalhadores afastados do trabalho $(\mathrm{n}=5)$ com diagnósticos médicos estabelecidos para LER/DORTs e alguns com mais de um diagnóstico, sendo quatro do gênero feminino e um do gênero masculino. A idade variou entre 36 e 52 anos, a escolaridade entre ensino fundamental completo $(\mathrm{n}=3)$ e incompleto $(\mathrm{n}=1)$, e ensino superior incompleto $(\mathrm{n}=1)$. As profissões variaram entre cozinheira $(\mathrm{n}=1)$, costureira $(\mathrm{n}=1)$, assistente administrativa $(n=1)$, auxiliar de serviços gerais $(n=2)$, sendo casado $(n=4)$ e um separado $(n=1)$. O tempo de afastamento variou entre 1 a 9 anos.

Visando manter o anonimato dos sujeitos participantes do estudo, foram utilizados nomes fictícios para identificar as entrevistas.

\section{Exigências físicas e psíquicas no trabalho}

\section{MATERIAIS E MÉTODOS}


Mesmo havendo diferenças em relação às tarefas e atividades das profissões e funções dos entrevistados, as exigências físicas foram apontadas como influenciadores para o surgimento de sintomas osteomusculares:

“(...) O movimento era repetitivo (...) você tinha que fazer sem descanso, (...) não tinha o direito de levantar e nem olhar pro lado, porque se olhasse, perguntava (o supervisor) o que era que você estava olhando. Então você não tinha nem o direito de parar um pouquinho pra estirar um braço, pra relaxar(...)." (Margarida, 52 anos, Costureira)

“(...) $\mathrm{O}$ correto era apurar, estruturar, fazer as guias e passar pro financeiro, mas eu não conseguia diante do montante de documentos (...) não era informatizado, era à mão, tinha que fazer rápido, era exigido (...) quando comecei a sentir dores fortíssimas na mão." (Violeta, 36 anos, Assistente administrativa)

“(...) Eram dez andares de apartamentos, mezanino, a garagem, o salão de festas que era em cima .(...) Quando era pra lavar a escadaria (exemplo) não tinha torneira nos andares. Então eu tinha que pegar água no salão de festas e descer pela escadaria ou pegar lá na garagem (...) e subir com os baldes, porque o elevador de serviço era só pra feira, cachorro e mala. E quando tinha que tirar o lixo também tinha que ser pela escadaria, (...) ". (Dália, 37 anos, Auxiliar de serviços gerais).

Havia repetitividade de movimentos e, em algumas situações, ritmo acelerado, impossibilidade de pausas, supervisão rígida e transporte manual de cargas. Em determinadas situações, além da repetitividade e exigências de ritmo acelerado de trabalho, havia pressão temporal por parte do supervisor. Estas imposições muitas vezes fazem com que os trabalhadores vão além de suas capacidades físicas. O ritmo acelerado de trabalho, a repetitividade de movimentos e a insuficiência de pausas, podem favorecer o desgaste físico e mental. É sempre necessária certa flexibilidade em relação ao ritmo de trabalho, para evitar a fadiga e tensão muscular. Existem vários fatores que causam impacto na saúde física e mental do trabalhador, tais como os fatores relacionados ao ritmo e tempo, jornadas longas com poucas pausas, pressões das chefias, entre outros (SILVA et al., 2009).

Para Heloani e Lancman (2004), o trabalho tem importância na função psíquica e é um dos grandes alicerces na constituição do sujeito e sua rede de significados. O trabalho ocupa lugar central na vida de muitas pessoas e apresenta múltiplos significados pessoais e sociais. É um elemento chave na formação das coletividades humanas, uma vez que a vida coletiva se organiza, em geral, em torno do trabalho. É também capaz de provocar diferentes graus de motivação e satisfação no trabalhador.

Para que não haja uma descompensação mental, o sujeito utiliza mecanismos de defesa, na tentativa de minimizar o sofrimento. No trabalho parcelado e repetitivo, onde há pouca comunicação entre os colegas de trabalho e muita rigidez na organização, há pouco espaço para mecanismos de defesa (DEJOURS, 1992). Há mecanismos de defesa individuais e coletivos: o primeiro está interiorizado, persistindo mesmo sem presença física de outros, enquanto que o segundo, a estratégia coletiva, não se sustenta sem um consenso, dependendo de questões externas ao sujeito (DEJOURS et al., 1994) .

Dentre as estratégias coletivas de defesa frente a situações de perigo estão: a banalização do risco e a negação do perigo. Nas situações onde há fragmentação de tarefas e repetitividade são descritas estratégias de defesa individuais tais como a aceleração da produção e a hiperatividade (HELOANI; LANCMAN, 2004). A idéia de que de que agir mais rápido faz "o tempo passar mais rápido" é considerada também uma estratégia defensiva relacionada ao surgimento da doença (MERLO et al, 2003. Alguns trabalhadores também aumentam espontaneamente as cargas produtivas em busca de reconhecimento pelo trabalho (GHISLENI; MERLO, 2005). Dejours (2008) argumenta que as empresas sabem que usando da ameaça da demissão e a consequente concorrência de trabalhadores à procura de emprego, elas podem intensificar o trabalho dos operadores.

O funcionamento psíquico, em relação aos pensamentos mobilizados pelos afetos, torna-se um obstáculo para a concentração exigida na produção. O trabalhador intensifica seus esforços e se impõe a aceleração, para minimizar o entorpecimento da atividade pelas expressões afetivas do sofrimento tais como angústia e a raiva (DEJOURS, 2008).

\section{Conflitos com supervisores no trabalho}

Outro aspecto encontrado foi aquele relacionado aos conflitos com os supervisores, que geram desgaste e sofrimento para os trabalhadores:

“(...)eles humilhavam a gente. Ela ( a supervisora) descia pra chamar a atenção de alguém, ela descia e brigava com a pessoa na frente de todo mundo! (...) falava coisas pra humilhar!" (Rosa, 52 anos, Cozinheira)

“(...) ela falou assim, que nós éramos um monte de 
vagabunda (...) que não queria trabalhar (...) Ela brigava! (...) humilhava... Se fosse só brigar, tava ótimo! Mas, não! Ela humilhava as pessoas que levantavam!" (Margarida, 52 anos, Costureira).

“(...) o chefe falava (...) se vira, arruma o carro, esse carro tem que sair às 4:00h da manhã(...) então a gente tinha que se virar, ele gritava: vocês estão aqui para trabalhar! Vocês estão ganhando pra isso!" (Pinheiro, 42 anos, Auxiliar de serviços gerais).

Muitas vezes o trabalhador se sujeita a obedecer os supervisores, por temer perder seu emprego, o que gera insegurança (SOUZA JUNIOR, 2008). Esse modo de tratar o trabalhador pode desencadear diferentes sentimentos, entre eles de menos valia, de inutilidade, decorrentes também da falta de reconhecimento pelo trabalho. O reconhecimento no trabalho é que permite o desenvolvimento da subjetividade e a transformação do sofrimento em prazer (DEJOURS et al., 1994). Quando o reconhecimento não existe, o sentimento de menos valia acaba por contaminar outras situações da vida diária e familiar e há risco de prejuízo á saúde mental (LANCMAN, 2004; DEJOURS, 2007).

\section{Sintomas dolorosos no trabalho}

Em várias situações os trabalhadores sentiam dores osteomusculares durante o trabalho:

“(...) eu sentia dor, eu sentia muita dor. Ela (supervisora) pegava no meu pé, ela dizia que eu não tinha nada, que eu tava enrolando o trabalho. Você está vendo que você tá doente e aquela pessoa (supervisor) não acredita." (Margarida, 52 anos, Costureira)

“(...) você toma um (analgésico) e vai aliviando. Quando ela (dor) começa a ficar insuportável aí fica mais difícil, né? E era quando eu ia para o pronto socorro(...). (Dália, 37 anos, Auxiliar de serviços gerais)

“(...) chegava em casa e tomava remédio e passava (...)eu estava com dor, mas ia trabalhar, eu tinha que lidar com a dor, eu tinha que trabalhar, né?" (Pinheiro, 42 anos, Auxiliar de serviços gerais).

Muitos trabalhadores sentem dores osteomusculares até não suportarem mais. A dor é invisível e quando é comunicada, muitas vezes há desconfiança, como se os trabalhadores estivessem fingindo o adoecimento para se afastarem (GAEDKE; KRUG, 2008). Além das estratégias de defesa citadas há o medo de ser desprezado, de fracassar, do desemprego, e de ser excluído do grupo. Esse conjunto de sentimentos pode favorecer a "banalização" dos sintomas dolorosos. Em todas essas situações se pode afirmar que o trabalho gera sofrimento e este pode ser patológico.

O medo desliga os trabalhadores do seu próprio sofrimento físico e psíquico e de seus pares, quando não se fala sobre as pressões ou sobre a dor e cada um vive na solidão (MERLO et al., 2003). As estratégias defensivas são necessárias à proteção da saúde mental contra os efeitos maléficos do sofrimento e podem também funcionar como uma armadilha que insensibiliza contra aquilo que faz sofrer (DEJOURS, 2007). Os argumentos apresentados mostram que se fosse dada a devida atenção aos sinais e sintomas osteomusculares iniciais, talvez não houvesse tantos quadros clínicos agravados e afastamentos do trabalho por LER/ DORT.

\section{A Perícia do Instituto Nacional do Seguro Social (INSS)}

Uma vez afastados, estes trabalhadores passaram por perícias do INSS, que geraram desgaste e sofrimento:

“(...) do perito, olhar pra você e dizer assim: - Olha, você é um custo pro INSS... você é um peso pro INSS (...) você é muito nova, tem que trabalhar (...) Eu ouvia aquilo, eu engolia aquilo .e eu saí chorando dali (...).(Violeta, 36 anos, Assistente administrativa).

(...) contribuo desde os 18 anos e agora que preciso, sou mal tratada com a forma que eles agem conosco, a pessoa só consegue se afastar se parecer que está morrendo." (Dália, 37 anos, Auxiliar de serviços gerais).

“(...) sempre é médico diferente. Então, é uma coisa que eles armam e você não se sente bem. (...) agora eu peguei um bom (...) mas eu sei lá, da outra perícia que eu vou pegar" (Margarida, 52 anos, Costureira)

Durante as perícias, as trabalhadoras passaram por algumas situações desagradáveis, de descaso pela doença. A invisibilidade da doença expõe os trabalhadores a humilhações, discriminação e preconceito por parte de chefes, colegas de trabalho, médicos e familiares, que podem acusá-los de simulação (SCOPEL, 2005). Certamente existem sujeitos que simulam incapacidades e doenças, o que gera revolta naqueles que apresentam acometimentos reais, mas tal situação não pode justificar a generalização e a postura hostil dos peritos, que penaliza os trabalhadores que necessitam do afastamento:

“(...) tem muita gente que se encontra afastado e não tem nada. Que conhece um psiquiatra e pega um atestado de que tem depressão profunda e fica afastado porque não quer trabalhar (...) acabam generalizando, achando 
que todos os segurados agem da mesma forma. (...) Eles precisam saber diferenciar." (Violeta, 36 anos, Assistente administrativa).

Em estudo de Ramos et al. (2010) junto a trabalhadores afastados por LER/DORT, houve associações com a depressão decorrente de perda de fatores que geram reconhecimento aos sujeitos (identidade no trabalho, na família e no círculo social). A situação de afastamento não é vista pelos membros da família como temporária para tratar de uma doença adquirida no trabalho; é vista, na maioria das vezes, como "desocupação", situação carregada de valores negativos (BRASIL, 2001).

Como não são os mesmos médicos que executam as perícias, e supostamente diante das dificuldades em discriminar as simulações, a cada consulta há necessidade de novas comprovações, passando os sujeitos por uma peregrinação de consultas médicas, e em busca de especialistas para as análises de diagnósticos dos quadros clínicos. Nas perícias, os trabalhadores afastados são constantemente questionados, como se quisessem estar na situação em que estão, o que agrava ainda mais o sentimento de impotência e desenvolvimento dos quadros de depressão (RAMOS et al., 2010). Essa peregrinação em médicos e vários serviços de saúde para conseguirem um diagnóstico, é um fator de sofrimento, pois cada especialista dá um novo diagnóstico e indica um novo tratamento (GAEDKE; KRUG, 2008).

O afastamento do trabalho também traz um contexto de incapacidade, carregado de significados. Entre os afastados do trabalho por LER/DORT se percebeu o sentimento de desvalorização, a percepção do desperdício dos anos de vida decorrente do adoecimento, discriminação para o mundo do trabalho, atestado público de declínio profissional, entre outros (NEVES; NUNES, 2009).

\section{Dores no cotidiano da vida do afastado}

Afastados do trabalho, os entrevistados passaram também por dificuldades no cotidiano de vida, relacionadas à presença de dores crônicas:

“(...) Tem dia que me dói até assim no meu pescoço, por aqui tudo (braço), me dói. Eu não consigo levantar, eu não consigo jogar ele (cabelo) pra frente, nem pra trás. (...)E dependendo do movimento que eu fizer com a mão, me dói, até pra andar (...)." (Margarida, 52 anos, Costureira)

“(...) eu não conseguia vestir uma blusa, assim, fechada(...). Outro dia, eu tava sentindo tanta dor, (...) eu tinha ido num cardiologista e não conseguia tirar o casaco(...) não consigo erguer o braço. (Rosa, 52 anos, Cozinheira)
A dor crônica afeta o cotidiano dos entrevistados e uma das formas mais usuais de aliviá-la é fazendo uso de medicamentos, o que pode levar á dependência física e psíquica (GAEDKE; KRUG, 2008). Os relatos mostram que as dores vão além da questão física e que geram sentimentos de incapacidade para o desempenho de ações básicas no cotidiano, como vestir-se e pentear os cabelos. A queixa sobre outros sintomas dolorosos além dos comumente encontrados nos diagnósticos clínicos específicos parece também gerar dúvidas e desconfianças nos peritos.

Os relatos revelaram que os trabalhadores demonstram estranhamento em relação aos seus corpos, como se não lhes pertencessem. Para abordar essa questão é necessário conhecer alguns limites do corpo em relação às capacidades físicas e saber lidar com as limitações funcionais, para promover a aceitação das novas condições. Deve-se ter conhecimento também sobre os movimentos que podem desencadear os sintomas, e permitir, quando possível, que os familiares auxiliem em tarefas que possam desencadeálos, evitando sobrecargas, etc.

A incapacidade física e emocional tende a suspender as atividades de vida diária, de dona-de-casa e esposa e as mulheres não conseguem se adaptar à nova vida que lhes é imposta, acabando, por vezes, a manifestarem quadros depressivos (GAEDKE; KRUG, 2008). O mesmo pode ocorrer com os homens na presença de sentimentos de menos valia, impotência, raiva, ou de não ser tão capaz como antes em ajudar nas atividades domésticas "pesadas".

Diante das questões abordadas, salienta-se neste estudo a importância de investigações e intervenções multiprofissionais nas LER/DORT, tanto no âmbito de atenção primária, secundária e terciária à saúde, sendo o terapeuta ocupacional um profissional fundamental na equipe.

\section{CONSIDERAÇÕES FINAIS}

Este estudo traz questões acerca dos impactos da organização do trabalho no surgimento de doenças osteomusculares relacionadas ao trabalho, entre eles as exigências de repetitividade, poucas pausas, supervisão rígida e até agressiva.

Coloca reflexões teóricas que mostram que há ligações claras entre o desenvolvimento de sintomas osteomusculares e o sofrimento no trabalho e que a negação desse vínculo favorece os afastamentos por LER/DORT.

No contexto contemporâneo as características de intensificação do trabalho e predomínio de visão de diminuição de custos contribuem fortemente com o aumento de agravos a saúde e requer mudanças. 
Diante do aumento de trabalhadores afetados por LER/DORT são frequentes as propostas de intervenção da ginástica laboral, porém sem intervenções que promovam melhorias nas condições de trabalho e em aspectos da organização do trabalho, por exemplo, estas ações não são suficientes, pois é necessário agir sobre as causas dos problemas.

Os trabalhadores afastados por LER/DORT apresentam repercussões na saúde mental que podem desencadear transtornos mentais, dependendo de como os sujeitos conseguem se adaptar e da eficácia de suas estratégias de defesa.
Os sujeitos demonstraram desgaste e sofrimento diante das situações de perícia, evidenciando as dificuldades em terem que comprovar, a cada perícia, a presença de doença.

Convivem com dores crônicas para a realização de atividades cotidianas. Revelam ainda desgaste e sofrimento frente às questões de sobrecargas no trabalho, maus tratos em relação aos supervisores, invisibilidade da doença $\mathrm{e}$ descaso de peritos.

Pareceu também haver conflitos de identidade social, sentimentos de inutilidade, de desqualificação, revolta, decorrentes da situação de afastamento do trabalho.

ALENCAR, M. C. B.; OTA, N. H. The work retirement due to RSI/WMSD: impact on mental health. Rev. Ter. Ocup. Univ. São Paulo, v. 22, n. 1, p. 60-67, jan./abr. 2011.

\begin{abstract}
The objective of this study was to investigate about worker's retirement of workrelated musculoskeletal disorder -WRMSD and discuss about repercussions on mental health from subject's subjective perceptions. The study is exploratory and descriptive study with qualitative data. There were selected retired workers affected by musculoskeletal disorders, which were attended in stage activities next to the course of Occupational Therapy of the Federal University of São Paulo, in 2009. There was elaborated a script and realized partially opened interviews about perceptions of how was the work, how he or she got sick, situations and difficulties related to the work and nowadays. Participated in this study five (5) subjects, both sex, age in between 36 and 52 years old. It was verified waste and suffering next to organizational aspects, presence of pain during work, symptoms and illness invisibility, functional difficulties in daily activities, and others. The study promotes some reflections about the worker's illness and retirement processes and repercussions on mental health.
\end{abstract}

KEY WORDS: Sick leave; Cumulative trauma disorders; Mental health; Work/psychology; Occupational therapy.

\title{
REFERÊNCIAS
}

BARDIN, L. Análise de conteúdo. Lisboa: Edições 70, 2010.

BRASIL. Ministério da Saúde. Lesões por esforços repetitivos (LER). Distúrbios osteomusculares relacionados ao trabalho (DORT). Brasília, 2001.

BRASIL. Ministério da Saúde. Saúde do trabalhador. Cadernos de Atenção Básica, nº 05. Brasília, 2002.

BRASIL. Ministério do Trabalho e Emprego. LER/DORT programa de prevenção. São Paulo: Ministério do Trabalho e Emprego, 2006.

BRASIL. Ministério da Previdência Social. Instrução normativa INSS/DC No 98, de 05 de dezembro de 2003 - DOU, 10 dez.
2003. Disponível em: <http://www81.dataprev.gov.br/sislex/ imagens/paginas/38/inss-dc/2003/anexos/IN-DC-98-ANEXO. htm>. Acesso em dez. 2010.

DEJOURS, C. A loucura do trabalho: estudo de psicopatologia do trabalho. São Paulo: Ed. Cortez, 1992.

DEJOURS, C.; ABDOUCHELI, E.; JAYET, C. Psicodinâmica do trabalho: contribuições da escola dejouriana à análise da relação prazer, sofrimento e trabalho. São Paulo: Atlas, 1994.

DEJOURS, C. Subjetividade, trabalho e ação. Revista Produção, v. 14, n. 3, p. 27-34, 2004.

DEJOURS, C. A banalização da injustiça social. Rio de Janeiro: 
ALENCAR, M. C. B.; OTA, N. H. O afastamento do trabalho. Rev. Ter. Ocup. Univ. São Paulo, v. 22, n. 1, p. 60-67, jan./abr. 2011.

Ed. FGV, 2007.

GAEDKE, M. A.; KRUG, S. B. F. Quem sou eu? A identidade de trabalhadoras portadoras de LER/DORT. Revista Textos \& Contextos, Porto Alegre, v. 7, n. 1. p. 120-137, 2008.

GHISLENI, A. P.; MERLO, A. R. C. Trabalhador contemporâneo e patologias por hipersolicitação. Psicologia: Reflexão e Crítica, v. 18, n. 2, p. 171-176, 2005.

HELOANI, J. R.; LANCMAN, S. Psicodinâmica do trabalho: o método clínico de intervenção e investigação. Revista Produção, v. 14, n. 3, p. 77-86, 2004.

LANCMAN, S. (Org). Saúde, trabalho e terapia ocupacional. São Paulo: Ed. Roca, 2004.

LANCMAN, S.; SZNELWAR, L. I. (Orgs.). Christophe Dejours: Da psicopatologia à psicodinâmica do trabalho. Rio de Janeiro, Ed. Fiocruz: Paralelo, 2008.

LANCMAN, S; UCHIDA, S. Trabalho e subjetividade. Cadernos de Psicologia Social do Trabalho, v. 6, p. 77-88, 2003.

MERLO, A. R. C.; VAZ, M. A.; SPODE, C. B.; ELBERN, J. L. G.; KARKOW, A. R. M.; VIEIRA, P. R. B. O trabalho entre prazer, sofrimento e adoecimento: a realidade dos portadores de lesões por esforços repetitivos. Psicologia \& Sociedade, v. 15, n. 1, p. 117-136, 2003.

MERLO, A.R.C.; JAQUES M.G.C.; HOEFEL, M.G.L. Trabalho de grupo com portadores de LER/DORT: relato de experiência. Psicologia: Reflexão e Crítica, v. 14, n. 1, p. 253-258, 2001.

NEVES, R. F; NUNES, M. O. Incapacidade, cotidiano e subjetividade: a narrativa de trabalhadores com LER/DORT. Interface: Comunicação, Saúde e Educação, v. 13, n. 30, p. 55$56,2009$.

Recebido para publicação: 24/10/10

Aceito para publicação: 10/05/11
OLIVEIRA, E. Toyotismo no Brasil: desencantamento da fábrica, envolvimento e resistência. São Paulo: Ed. Expressão Popular, 2004.

PASTRE, E. C.; CARVALHO FILHO, G.; PASTRE, C. M.; PADOVANI, C. R.; ALMEIDA, J. R.; NETTO JÚNIOR, J. Queixas osteomusculares relacionadas ao trabalho relatadas por mulheres de centro de ressocialização. Cadernos de Saúde Pública, v. 23, n. 11, p. 2605-2612, 2007.

RAMOS, M. Z.; MERLO, A. R. C.; POERSCH, A. L.; VEECK, C.; HEISLLER, S. Z.; VIEIRA, J. A. Trabalho, adoecimento e histórias de vida em trabalhadoras de indústria calçadista. Estudos de Psicologia, v. 15, n. 2, 2010.

RAMOS, M. Z.; TITTONI, J.; NARDI, H. C. A experiência de afastamento do trabalho por adoecimento vivenciada como processo de ruptura ou continuidade nos modos de viver. Cadernos Psicologia e Trabalho, v. 11 n. 2. p. 209-221, 2008.

SCOPEL, M. J. Retorno ao trabalho: trajetória de trabalhadores metalúrgicos portadores de LER/DORT. 2005. 130f. Dissertação (Mestrado em Psicologia Social e Institucional) - Universidade Federal do Rio Grande do Sul, Porto Alegre, 2005.

SILVA, S. R.; GUIMARÃES, E. V.; RODRIGUES, A. M. V. N. Aspectos relacionados ao processo de retorno ao trabalho de indivíduos com desordens músculo-esqueléticas do membro superior: uma bibliografia comentada. Revista de Terapia Ocupacional da Univ. São Paulo, v. 18, n. 1, p.3 8-43, 2007.

SOUSA JUNIOR, M. V. Análise da qualidade de vida do trabalhador portador de DORT em cidades agrícolas: O caso do Vale do São Patrício. 2008. 113f. Dissertação (Mestrado em Ciências Ambientais e Saúde) - Pontifícia Universidade Católica de Goiás, Goiânia, 2008. 